\title{
ADAPTIVE SIGNAL DECOMPOSITION AND FILTERING USING BINOMIAL FILTERS APPLIED TO THE GROUND-ROLL ATTENUATION
}

\author{
Cristian D. Ariza A. ${ }^{1}$ and Milton J. Porsani ${ }^{2}$
}

\begin{abstract}
The ground-roll is a type of noise normally present in land seismic data. It strongly harms the signal-to-noise ratio, and interferes in several stages of the seismic data processing, strongly affecting the final quality of the obtained seismic images. For the attenuation of the ground-roll we propose an adaptive filtering method that uses binomials filters obtained from the convolution of pairs of dipoles $(1, c)$ and $(c,-1)$. The coefficient $c$ corresponds to the first coefficient of the prediction error operator, obtained through the Burg algorithm. This filtering method allows for the decomposition of signals in frequency bands, from the lowest frequency band to the highest band. The method is applied in adaptive form, in sliding windows of time, adapting themselves to the variations in the frequency content of the data. Its implementation and use in seismic data processing is relatively simple and computationally efficient.
\end{abstract}

Keywords: seismic noise, signal-to-noise ratio, adaptive filters, Burg algorithm, seismic signal decomposition.

RESUMO. 0 ground-rol/é um tipo de ruído normalmente presente nos dados sísmicos terrestres. Ele prejudica muito a razão sinal-ruído e interfere em vários estágios do processamento de dados sísmicos, afetando fortemente a qualidade final das imagens sísmicas obtidas. Para atenuação desse ruído, propomos um método de filtragem adaptativa que utiliza filtros binomiais construídos a partir da convolução de pares de dipolos $(1, c)$ e $(c,-1)$. 0 coeficiente $c$ corresponde ao primeiro coeficiente do operador de erro de predição e é obtido através do algoritmo de Burg. Este método de filtragem adaptativa permite a decomposição de sinais em bandas de frequência, desde a banda de mais baixa frequência até a de mais alta. 0 método é aplicado na forma adaptativa, utilizando janelas deslizantes de tempo, adaptando-se às variações do conteúdo de frequência dos dados ao longo do registro sísmico. Sua implementação e uso, no processamento de dados sísmicos, é relativamente simples e computacionalmente eficiente.

Palavras-chave: ruídos sísmicos, relação sinal-ruído, filtragem adaptativa, algoritmo de Burg, decomposição do sinal sísmico.

\footnotetext{
${ }^{1}$ Universidade Federal da Bahia (UFBA), Center for Research in Geophysics and Geology (CPGG), Rua Barão de Geremoabo s/n, 40170-115 Salvador, BA, Brazil. Phone: +55(71) 3283-8530 - E-mails: cristian.ariza@ufba.br; arizacristian@gmail.com

2 Universidade Federal da Bahia (UFBA), Center for Research in Geophysics and Geology (CPGG) and National Institute of Science and Technology of Petroleum Geophysics (INCT-GP/CNPq), Rua Barão de Geremoabo s/n, 40170-115 Salvador, BA, Brazil. Phone: +55(71) 3283-8530; Fax: +55(71) 3283-8501 - E-mail: porsani@ufba.br
} 


\section{INTRODUCTION}

One of the most significant challenges in processing of seismic data is to filter different types of noises. Ground-roll is one of the main types of coherent noise in land seismic data. It has the significant characteristics of relatively low velocity, low frequency, high amplitude and strong energy (Sheriff, 2002). Because of its dispersive nature and low velocity, ground-roll masks the shallow reflections at near offsets and deep reflections at far offsets (Saatcilar \& Canitez, 1988; McMechan \& Sun, 1991; Saatcilar \& Canitez, 1994; Henley, 2003) and also distorts reflection events by interfering with them.

Ground-roll is one of the main coherent noises in petroleum seismic exploration, many methods have been introduced to attenuate this type of noise. Although the right choice of attenuation techniques is a matter of trial and error (Sheriff \& Geldart, 1995). The conventional methods can be divided into two groups. The first one can be summarized to filter method which is based on suppression of undesired parts of recorded data in the spectral domain, including high-pass and band-pass filtering, $f-k$ filtering (Embree et al., 1963; Treitel et al., 1967; Yilmaz, 2001) and the adaptive ground-roll attenuation method (Wang et al., 2012; Hosseini et al., 2015). These methods have their limitations. High-pass and band-pass filter may eliminate the low frequency component of effective waves since the frequency bands of ground-roll noise and reflections are often overlapped (Sirgue, 2006). The conventional $f-k$ filter would cause serious distortion of effective waves when the energy of ground-roll noise is much stronger than that of reflections (McMechan \& Sun, 1991; Liu, 1999; Tokeshi et al., 2006). The other one is wave field separation method based on ground-roll noise extraction and arithmetical subtraction of it from the raw shot gather in the $t-x$ domain, including Wiener-Levinson algorithm (Karsli \& Bayrak, 2004), Karhunen-Loève (K-L) transform (Gómez Londoño et al., 2005), wavelet transform (Deighan \& Watts, 1997) and Radon transform (Russell et al., 1990a,b).

There are different methods of decomposing a seismic signal used for suppressing the ground-roll: Empirical Mode Decomposition (EMD), developed by Huang et al. (1998) and used by Ferreira et al. (2013); singular value decomposition, SVD used by Porsani et al. (2010), Wavelet decomposition used by Deighan \& Watts (1997), decomposition by filtering frequency bands with binomial operators justified by Akansu \& Haddad (2001) and Vetterli \& Herley (1992) used by Ariza \& Porsani (2015) for attenuation ground-roll.

Filtering with binomial operators (Haddad, 1971; Vetterli \& Herley, 1992; Akansu \& Haddad, 2001), enable decomposition and perfect reconstruction of the signal through the linear combination of its components. The decomposition of a signal is made into frequency bands by means of a matrix operators $\widetilde{\mathbf{X}}$, which is obtained by weighting each column of the matrix $\mathbf{X}_{n}^{j}$ (obtained through the dipoles $(1,1)$ and $(1,-1))$. This procedure allows for the original signal shifted to the position $\widetilde{S}_{n}=S_{n} * \delta_{n-a}$. To recover the signal in the initial position just delay it for $a$ samples.

It can be shown that the construction of the matrix $\mathbf{X}$, through the dipoles $(1,1)$ and $(1,-1)$, is just a special case of a general breakdown binomial with dipoles $(\alpha, \beta)$ and $(\beta,-\alpha)$ where $\alpha$ and $\beta$ can be real or complex (in this work we will only consider the case real), where the values of $\alpha$ and $\beta$ beta can be arbitrarily chosen or may be obtained by the features given itself, creating infinite possibilities of decomposition. In the present paper we compute the dipoles adaptively, with $(1, c)$ and $(c,-1)$, where $c$ is the coefficient of the prediction error operator obtained by using the Burg algorithm.

\section{THEORY}

Following is presented a form of general binomial decomposition with dipoles $(\alpha, \beta)$ and $(\beta,-\alpha)$, where $\alpha$ and $\beta$ can be real or complex (in this text we will only consider the real case). The dipoles $(1,1)$ and $(1,-1)$ are a special case of this general representation (Boyd et al., 2001; Severo, 2008; Severo \& Schillo, 2009).

In the case of a binary decomposition of order $1(N=1)$, the operators matrix $\mathbf{X}$ is written as follows:

$$
\mathbf{X}=\left[\begin{array}{rr}
\alpha & \beta \\
\beta & -\alpha
\end{array}\right]=\left[\begin{array}{l}
\mathbf{y}_{0}^{T} \\
\mathbf{y}_{1}^{T}
\end{array}\right]=\left[\begin{array}{ll}
\mathbf{x}_{0} & \mathbf{x}_{1}
\end{array}\right]
$$

You can verify that $\mathbf{X}^{2}=\lambda \mathbf{I}$. For the case where $N=1$, $\lambda=\alpha^{2}+\beta^{2}$, so the matrix $\mathbf{X}^{-1}$ is:

$$
\mathbf{X}^{-1}=\frac{1}{\alpha^{2}+\beta^{2}}\left[\begin{array}{rr}
\alpha & \beta \\
\beta & -\alpha
\end{array}\right]
$$

The operator matrix $\widetilde{\mathbf{X}}$ is obtained, for example, selecting the first column of $\mathbf{X}^{-1}(a=0)$. This results in

$$
\widetilde{\mathbf{X}}^{0}=\left[\begin{array}{cc}
\frac{\alpha^{2}}{\alpha^{2}+\beta^{2}} & \frac{\beta^{2}}{\alpha^{2}+\beta^{2}} \\
\frac{\alpha \beta}{\alpha^{2}+\beta^{2}} & \frac{-\alpha \beta}{\alpha^{2}+\beta^{2}}
\end{array}\right]
$$

It should be noted that if the columns of the matrix $\widetilde{\mathbf{X}}$ are stacked, the result is $(1,0)^{T}$. 
Applying binary decomposition of order $1(N=1)$ to a discrete signal $\left\{S_{n}\right\}=\left\{s_{0}, \ldots, s_{M-1}\right\}$ is equivalent to performing the convolution of the original signal with each of the columns of the operator matrix $\widetilde{\mathbf{X}}^{0}$. The signal recovery is obtained by a simple stacking of the signal components.

$$
\begin{aligned}
\left\{R_{n}\right\} & =\left\{S_{n}\right\} *\left\{\widetilde{X}_{0}^{0}\right\}+\left\{S_{n}\right\} *\left\{\widetilde{X}_{1}^{0}\right\} \\
& =\left\{S_{n}\right\} *\left\{\widetilde{X}_{0}^{0}+\widetilde{X}_{1}^{0}\right\} \\
& =\left\{S_{n}\right\} *(1,0)^{T}=\left\{S_{n}\right\} *\left\{\delta_{n}\right\} \\
& =\left\{S_{n}\right\}
\end{aligned}
$$

The operators matrix $\mathbf{X}$ for any order $N$ (where $\mathbf{X}$ have $N+1$ columns) is calculated as follows:

$$
X_{n}^{r}=(\alpha, \beta)^{*(N-r)} *(\beta,-\alpha)^{* r}
$$

for $0 \leq r \leq N$. Remember that

$$
x^{* n}=\underbrace{x * x * x * \cdots * x * x}_{n}
$$

denotes $n$-times convolution, where $x^{* 0}=\delta_{0}, x^{* 1}=x$ and $\delta_{0}$ is the Kronecker delta.

The matrix generated, as shown previously, keeps the property of orthogonality between rows and columns, i.e., $\mathbf{y}_{i}^{T} \mathbf{x}_{j}=0$ for $i \neq j$ and $\mathbf{y}_{i}^{T} \mathbf{x}_{j}=\lambda^{N}$ for $i=j$. That is

$$
\mathbf{X}^{2}=\lambda^{N} \mathbf{I}
$$

where

$$
\lambda=\alpha^{2}+\beta^{2}
$$

calculating the inverse matrix as

$$
\mathbf{X}^{-1}=\frac{1}{\lambda^{N}} \mathbf{X}
$$

The property $\mathbf{X}^{2}=\lambda^{N} \mathbf{I}$ is particularly important in signal decomposition and filtering. We note that, despite of a scale factor, $\lambda^{N}, \mathbf{X}$ matrix is its own inverse. This property provides $N+1$ possibilities to decompose the original signal, each related to a particular column of the matrix $\widetilde{\mathbf{X}}^{a}(a=0,1, \ldots, N)$. The signal can be decomposed or restored as a linear combination of components, obtained by convolution of the original signal with the columns of the matrix $\widetilde{\mathbf{X}}^{a}$. Each component, $\left\{\widetilde{S}_{n}^{r}\right\}=\left\{\widetilde{X}_{n}^{r}\right\} *\left\{S_{n}\right\}$, will have a different frequency content depending on the values $\alpha$ and $\beta$ selected.

The values of $\alpha$ and $\beta$ can be arbitrary or can be calculated adaptively, using local characteristics of the data $\left\{S_{n}\right\}=$ $\left\{s_{0}, \ldots, s_{M-1}\right\}$. Consequently, the method is versatile and relatively simple to implement. It may be used for signal analysis or filtering, and there are many ways to perform the decomposition of a signal.

\section{RESULT}

In order to get local information from the data, the recursive Burg algorithm was used to obtain the first coefficient of the prediction error for a specified window's length (Burg, 1967). It is possible to generate dipoles $(1, c)$ and $(,-1)$, where $c$ is the first prediction error coefficient, for a given window. Taking into account the minimum phase property of the linear unit error prediction filters when they are calculated using the least squares method (Appendix $\mathrm{A}$ of $\mathrm{Chu}, 2004)$, the first coefficient is always negative less than one, then the first dipole $(1, c)$ is a differentiation operator allowing the capture of high frequency information (depending on the window width) and the second dipole $(c,-1)$ (both negative) would be an operator of integration which allows capturing low frequency information.

We use a 96 channel common-shot-point gather (Fig. 6A) acquired in the North-west Brazil (Tacutu Basin) to demonstrate the feasibility and applicability of the proposed method. The geophone interval is $50 \mathrm{~m}$. The length of the record is $4000 \mathrm{~ms}$ with a 4 ms sample interval.

There were tested different window sizes (from 20 ms to $2000 \mathrm{~ms})$, achieving the best contrast between areas with and without ground-roll with a $200 \mathrm{~ms}$ window. Figure 1 shown the values of the coefficient $c$, for the shot gather shown in Figure $6 \mathrm{~A}$. The presence of the ground-roll, corresponding to the low frequency areas, is marked by the lower amplitude values of the $c$ coefficients. More information about how was construct this graph, see appendix.

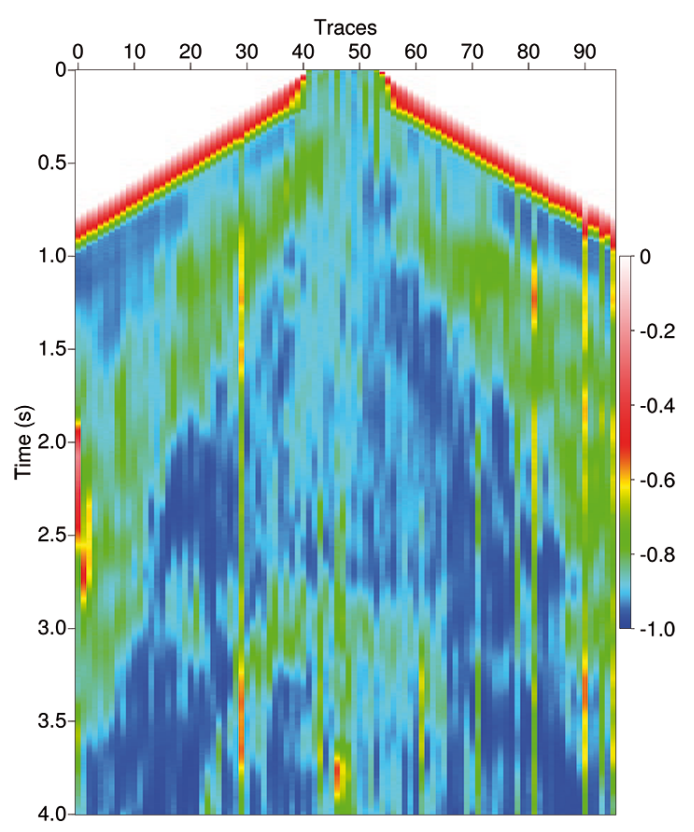

Figure 1 - Map of the prediction error coefficients, used to generate the binomials filters, corresponding to the shot gather in Figure 6A. 
The algorithms used to trace decomposition are shown below (Algorithm 1 and Algorithm 2).

\section{Signal decomposition and reconstruction}

To test the decomposition and perfect reconstruction of the signal it was used a level of decomposition $N=7$ weighted by the first column of the inverse matrix $(a=0)$. So the seismic traces in Figure $6 \mathrm{~A}$ is decomposed into 8 panels with different frequency content, from highest to lowest frequency. Figure 2 shows the corresponding average amplitude spectra. We note that generally the decomposed panels have lower amplitude spectra than the original.

Figure 3 shows four $\left(\widetilde{S}_{1}, \widetilde{S}_{3}, \widetilde{S}_{5}\right.$ and $\left.\widetilde{S}_{7}\right)$ of the eight decomposed panels. It can be seen that each decomposed shot gather has different frequency content. Air wave (or sound wave) noise, with an apparent velocity of about $340 \mathrm{~m} / \mathrm{s}$, can be identified in $\widetilde{S}_{1}$ (Fig. 3A). It is clear that air wave is a type of non- dispersive coherent noise, as same as body wave. As seen in panel $\widetilde{S}_{7}$, (Fig. 3D), reflections are heavily contaminated by largely dispersed ground-roll noise. The differences between the firsts panels, corresponding to higher frequencies, are minimal. The stack of all decomposed panels reconstruct the original shot gather. The error of the reconstruction is due to the numerical computational artifacts (Fig. 4).

\section{Ground-roll attenuation}

The weak reflections are invisible due to the interference of the strong ground-roll noise (Fig. 6A). Furthermore, the reflected events in the shot gather are even truncated due to the highamplitude of the ground-roll. The blue line in Figure 2 shows the average amplitude spectra of the ground-roll. We can see that mostly of its energy is concentrate between frequencies $1 \mathrm{~Hz}$ to $10 \mathrm{~Hz}$, overlapping with the frequencies content of the reflections, with occur dominantly between $10 \mathrm{~Hz}$ to $50 \mathrm{~Hz}$. Figure 3D shown
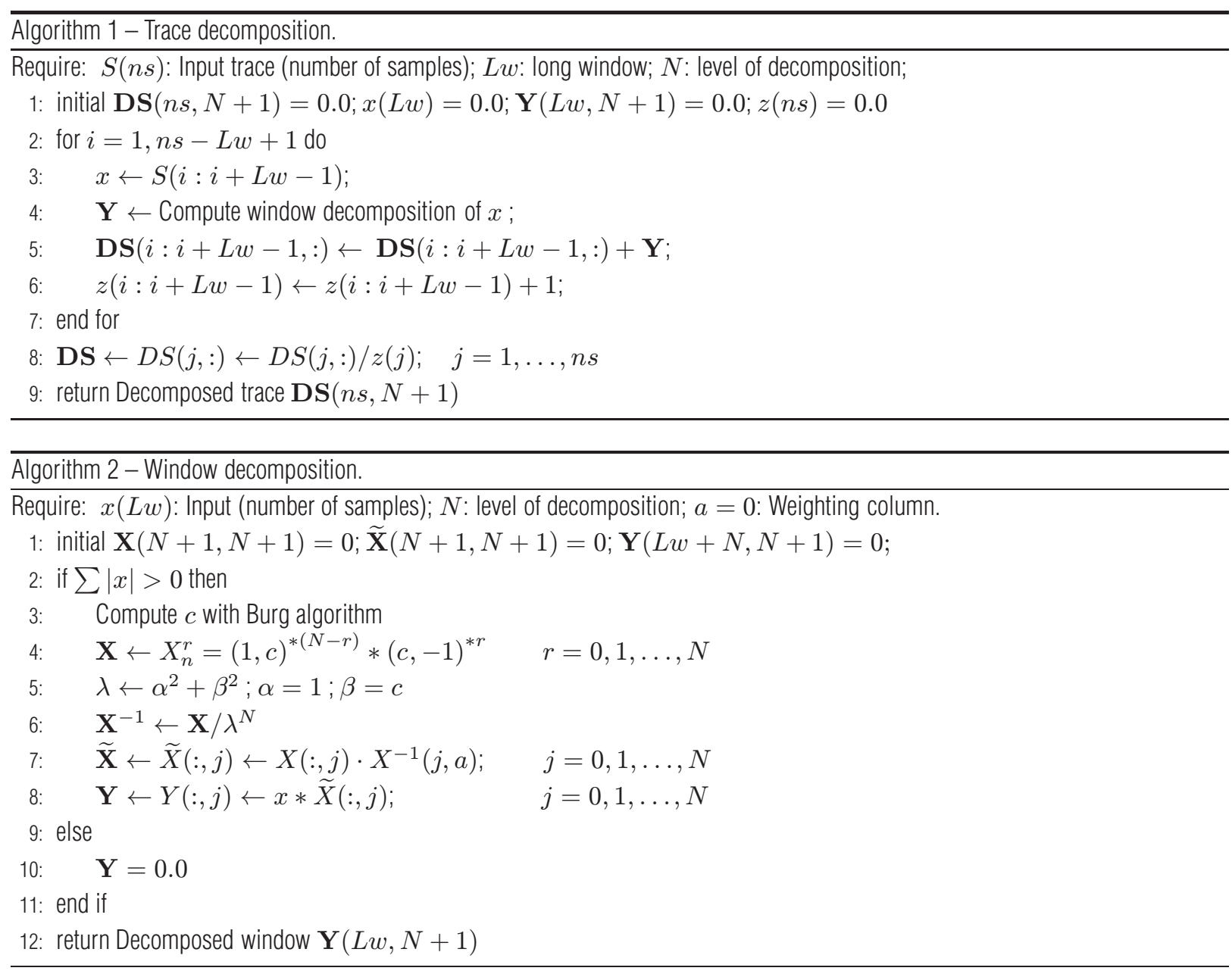


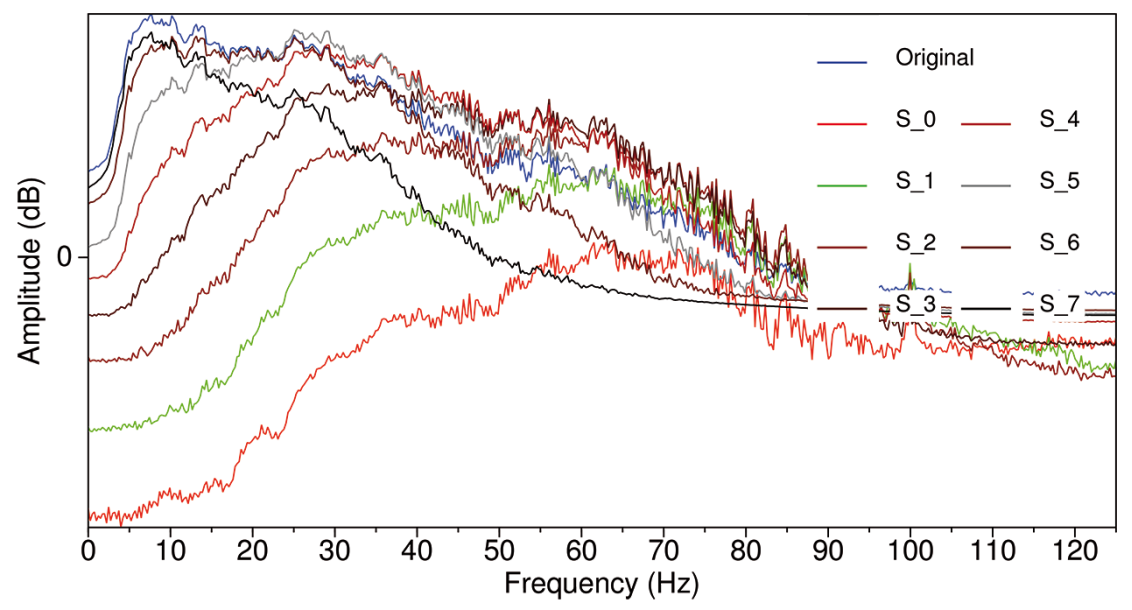

Figure 2 - Average amplitude spectra of the shot gather decomposition by using dipoles $(1, c)$ and $(c,-1)$ for $N=7$.

that the ground-roll may be successfully separated out from the original shot gather. Observing the amplitude spectra of the original and decomposed shot gathers (Fig. 2), we note that the dominant low frequency content may be formed by adding panels $\widetilde{S}_{6}$ and $\widetilde{S}_{7}$. Hence, a good option to mitigate the ground-roll is to reconstruct the signal by adding panels from $\widetilde{S}_{0}$ to $\widetilde{S}_{5}$, which we nominate as DB1c result. That is equivalent to subtract $\widetilde{S}_{6}$ and $\widetilde{S}_{7}$ from the original shot gather.

To validate the DB1c result we applied two others commonly used methods to filter the shot gather data: trapezoidal frequency band-pass filter $\left(f_{1}=10 \mathrm{~Hz}, f_{2}=20 \mathrm{~Hz}, f_{3}=60 \mathrm{~Hz}\right.$, and $f_{4}=70 \mathrm{~Hz}$ ) and $f-k$ filtering. Figure 5 show the average amplitude spectra of the filtered shot gathers. Since the frequencies bands of ground-roll and reflections are overlapped, the band-pass filter attenuate both, the low frequency component of the ground-roll and the signal. The $f-k$ filtering still retains strong ground-roll noise in the frequency band from $0 \mathrm{~Hz}$ to $20 \mathrm{~Hz}$, whereas the proposed method (DB1c) removed most part of the ground-roll.

Figure 6 shows comparisons between the original shot gather and results obtained by using frequency domain methods. All three methods provide ways to attenuate ground-roll, but bandpass filter has significant decrease amplitude drawback. $f-k$ filtering causes serious distortion of the reflection and the adaptive binomial filtering is more effective to the ground-roll attenuation, preserving better the reflections.

\section{CONCLUSIONS}

We presented an adaptive binomial filtering method where the filters are obtained by convolving dipoles. These dipole coefficients are associated with the prediction error operator and are computed by using the Burg algorithm. We show that the matrix associated with the binomial filter may be used to perform signal decomposition and/or filtering the data. We applied the method to filter the ground-roll in a shot gather. The obtained results showed the new approach is more effective when compared with the commonly used filtering methods working in the frequency domain. Below we summarize the main general characteristics of the proposed adaptive binomial filter:

- The implementation of the bank of binomial filters, at any level, allows for the decomposition and also for a perfect reconstruction of seismograms;

- Any additional processing may be performed in any of the decomposed signal or panel, which makes the method very versatile;

- The generation of adaptive binomial operator (filter) only involves dipoles convolution and their use in filtering of seismic data is considerably simple and computationally efficient;

- The signal decomposition/filtering is performed trace by trace. That property may be explored by using parallelization computing for processing of very large data volumes;

- The filtering method is robust, easy to implement, computationally efficient and requires few parameter setting by the user. 

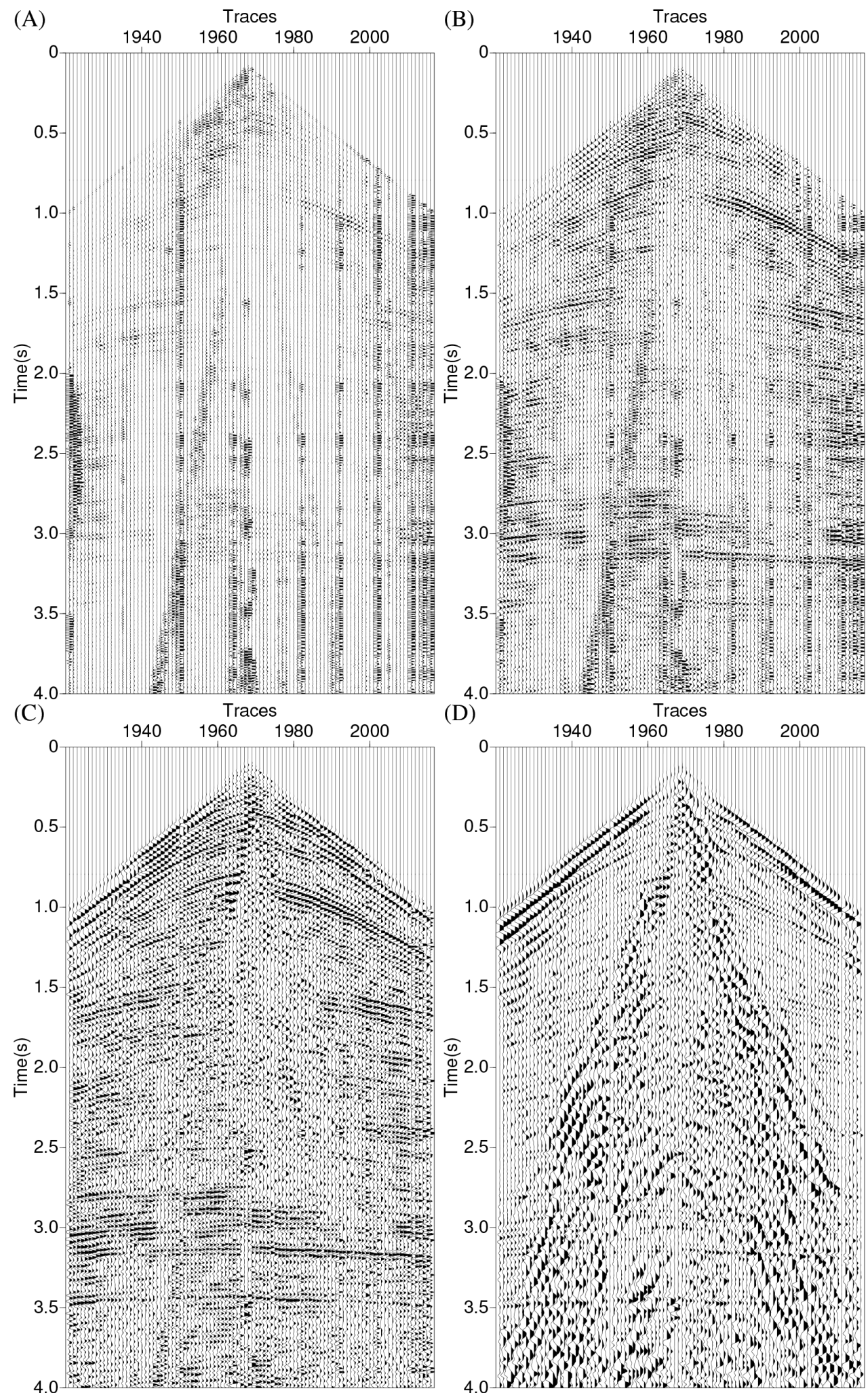

Figure 3 - Four of the eight decomposed shot gathers using the adaptive binomial decomposition method. $\widetilde{S}_{1}$ in (A), $\widetilde{S}_{3}$ in (B), $\widetilde{S}_{5}$ in (C) and $\widetilde{S}_{7}$ in (D). 


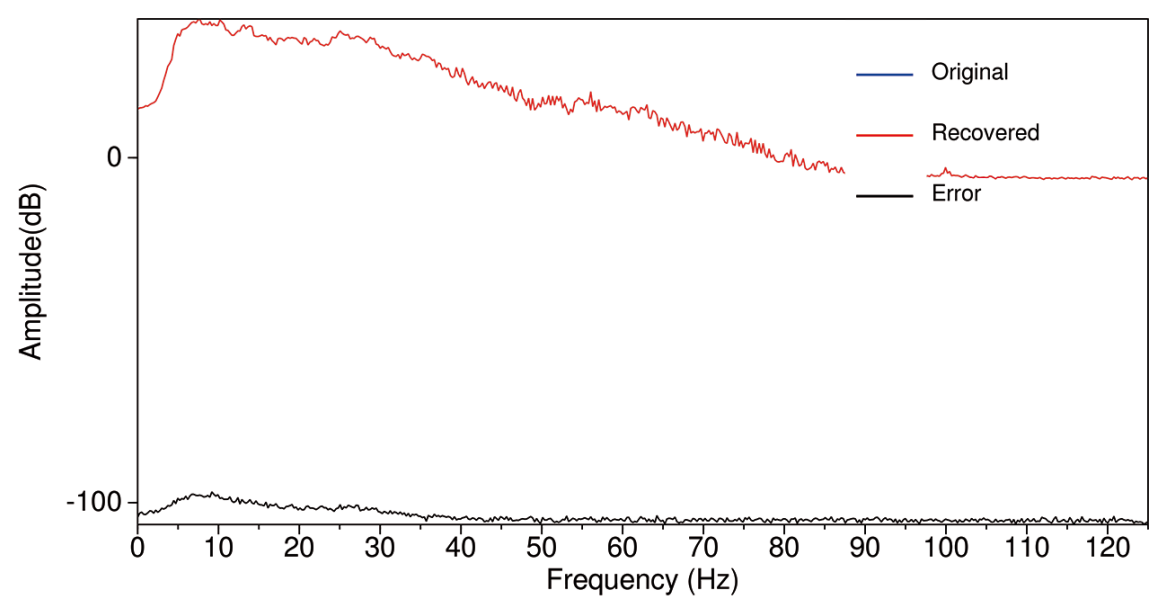

Figure 4 - Average amplitude spectra (in decibel scale) of the shot gather and perfect reconstruction results. The red line, the blue line, and the black line denote spectra of original data, perfect reconstruction and error, respectively. (Red and blue lines are coincident).
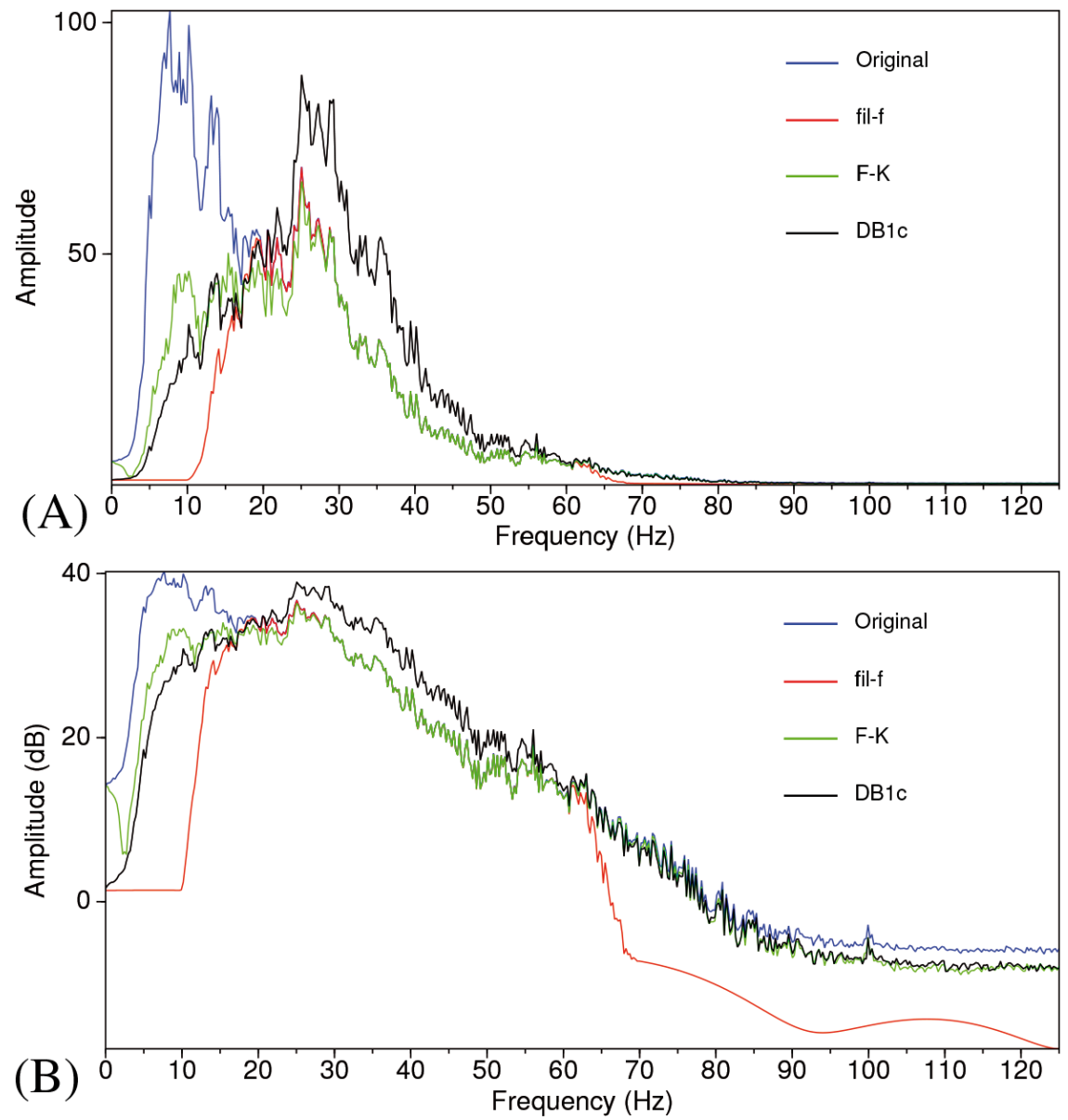

Figure 5 - Comparisons of the average amplitude spectra, in linear scale (A) and decibel scale (B), of the original and filtered shot gathers shown in Figure 6 . The red, blue, green and black lines denote spectra of original data and results after filtering using band-pass, $f-k$, proposed (DB1c) methods, respectively. 

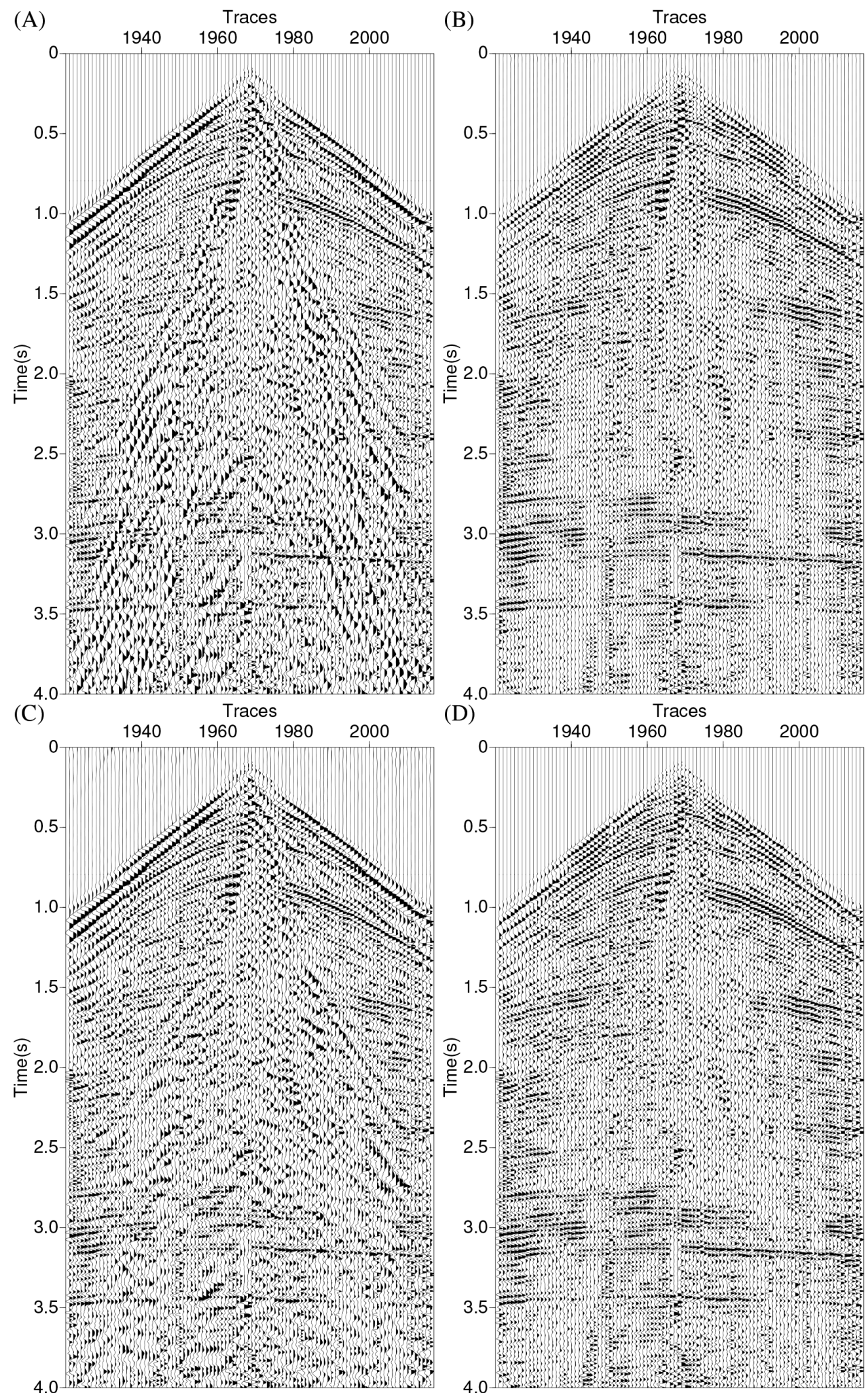

Figure 6 - Comparisons between the original shot gather and filtered results. The original shot gather in (A), results after band-pass in (B), results of the $f-k$ in (C), and the proposed method (DB1C) in (D). 


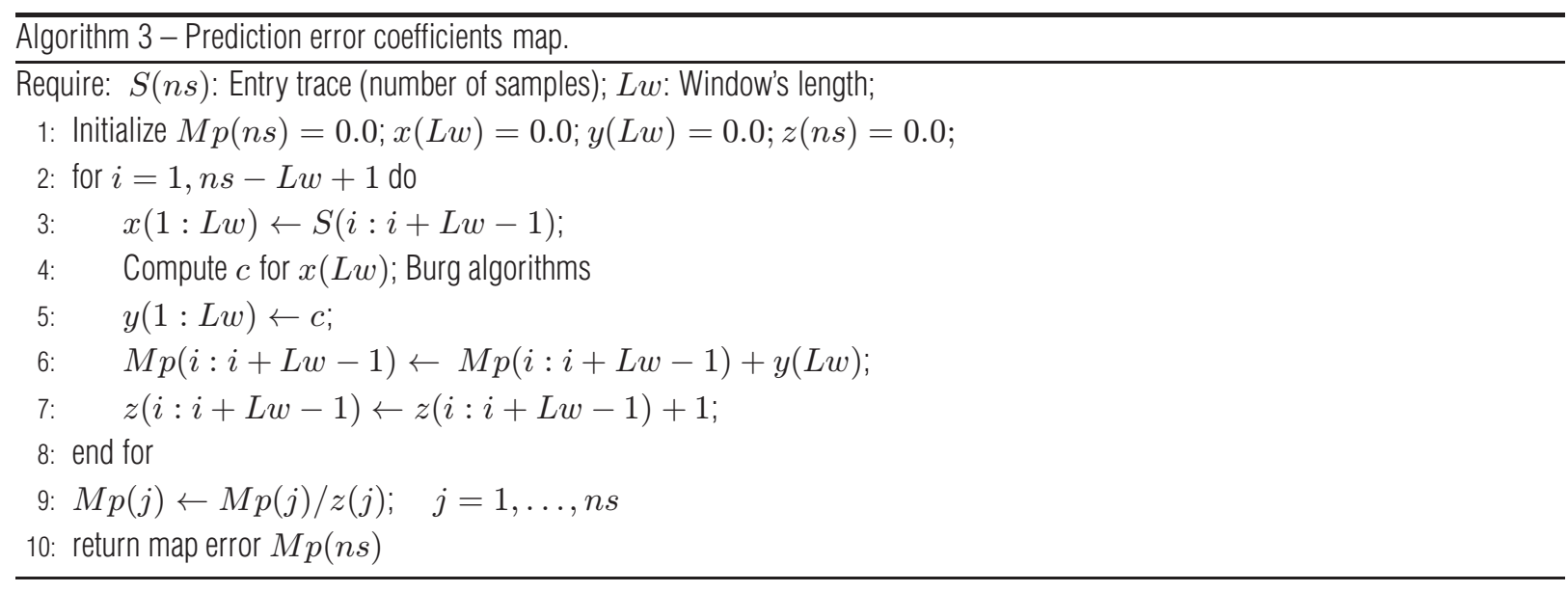

\section{APPENDIX}

For the obtaining of the data presented in Figure 1, the following procedure was followed for each seismic trace:

- The coefficient map begins with a value of 0.0 ;

- The value of the first coefficient error for the window's length is calculated using the Burg algorithm;

- The coefficient value is added to all the positions of the window's length in the coefficient map;

- The window is then moved one sample, and the previous two steps are repeated until the end of the trace.

At the end, an average is calculated as a function of the number of values added at each position of the coefficient map. This procedure is presented in the Algorithm 3.

\section{ACKNOWLEDGEMENTS}

The authors wish to express their gratitude to the Fundação de Amparo à Pesquisa do Estado da Bahia (FAPESB), INCT-GP, (CNPq), FINEP, PETROBRAS, for financial support.

\section{REFERENCES}

AKANSU AN \& HADDAD RA. 2001. Multiresolution Signal Decomposition: Transforms, Subbands, and Wavelets. Series in Telecommunications. Academic Press, 2nd ed.

ARIZA CD \& PORSANI MJ. 2015. Atenuação do ground-roll utilizando filtros binomiais. In: 14th International Congress of the Brazilian Geophysical Society \& EXPOGEF, Rio de Janeiro, Brazil, 3-6 August 2015, pp. 1345-1350. Brazilian Geophysical Society.

BOYD G, MICCHELLI CA, STRANG G \& ZHOU DX. 2001. Binomial matrices. Advances in Computational Mathematics, 14(4): 379-391.
BURG JP. 1967. Maximum entropy spectral analysis. In: 37th Annual International Meeting, pp. 34-41. Society of Exploration Geophysics.

CHU WC. 2004. Speech coding algorithms: foundation and evolution of standardized coders. John Wiley \& Sons.

DEIGHAN AJ \& WATTS DR. 1997. Ground-roll suppression using the wavelet transform. Geophysics, 62(6): 1896-1903.

EMBREE P, BURG JP \& BACKUS MM. 1963. Wide-band velocity filtering-the pie-slice process. Geophysics, 28(6): 948-974.

FERREIRA LES, PORSANI MJ, DA SILVA MG \& VASCONCELOS GL. 2013. Application of the empirical mode decomposition method to ground-roll noise attenuation in seismic data. Brazilian Journal of Geophysics, 31(4): 619-630.

GÓMEZ LONDOÑO E, CASTILLO LÓPEZ L \& KAZMIERCZAK TS. 2005. Using the Karhunen-Loève transform to suppress ground roll in seismic data. Earth Sciences Research Journal, 9(2): 139-147.

HADDAD RA. 1971. A class of orthogonal nonrecursive binomial filters. IEEE Transactions on Audio and Electroacoustics, 19(4): 296-304.

HENLEY DC. 2003. Coherent noise attenuation in the radial trace domain. Geophysics, 68(4): 1408-1416.

HOSSEINI SA, JAVAHERIAN A, HASSANI H, TORABI S \& SADRI M. 2015. Adaptive attenuation of aliased ground roll using the shearlet transform. Journal of Applied Geophysics, 112: 190-205.

HUANG NE, SHEN Z, LONG SR, WU MC, SHIH HH, ZHENG Q, YEN NC, TUNG CC \& LIU HH. 1998. The empirical mode decomposition and the Hilbert spectrum for nonlinear and non-stationary time series analysis. Proceedings of the Royal Society of London A: Mathematical, Physical and Engineering Sciences, 454: 903-995. The Royal Society.

KARSLI H \& BAYRAK Y. 2004. Using the Wiener-Levinson algorithm to suppress ground-roll. Journal of Applied Geophysics, 55(3): 187-197.

LIU X. 1999. Ground roll supression using the Karhunen-Loeve transform. Geophysics, 64(2): 564-566. 
MCMECHANG \& SUN R. 1991. Depth filtering of first breaks and ground roll. Geophysics, 56(3): 390-396.

PORSANI MJ, SILVA MG, MELO PE \& URSIN B. 2010. SVD filtering applied to ground-roll attenuation. Journal of Geophysics and Engineering, 7(3): 284.

RUSSELL B, HAMPSON D \& CHUN J. 1990a. Noise elimination and the radon transform, part 1. The Leading Edge, 9(10): 18-23.

RUSSELL B, HAMPSON D \& CHUN J, 1990b. Noise elimination and the radon transform, part 2. The Leading Edge, 9(11): 31-37.

SAATCILARR \& CANITEZ N. 1988. A method of ground-roll elimination. Geophysics, 53(7): 894-902.

SAATCILAR R \& CANITEZ N. 1994. The lattice filter in ground-roll suppression. Geophysics, 59(4): 623-631.

SEVERO NC. 2008. Matrices with convolutions of binomial functions and Krawtchouk matrices. Linear Algebra and its Applications, 429(1): 50-56.

SEVERO NC \& SCHILLO PJ. 2009. Matrices with convolutions of binomial functions, their determinants, and some examples. Journal of Algebra, Number Theory: Advances and Applications, 2(1): 51-57.
SHERIFF RE. 2002. Encyclopedic Dictionary of Applied Geophysics, USA.

SHERIFF RE \& GELDART LP. 1995. Exploration Seismology. Cambridge University Press.

SIRGUE L. 2006. The importance of low frequency and large offset in waveform inversion. In: 68th EAGE Conference and Exhibition incorporating SPE EUROPEC 2006.

TOKESHI JC, KARKEE MB \& SUGIMURA Y. 2006. Reliability of rayleigh wave dispersion curve obtained from $f-k$ spectral analysis of microtremor array measurement. Soil Dynamics and Earthquake Engineering, 26(2): 163-174.

TREITEL S, SHANKS JL \& FRASIER CW. 1967. Some aspects of fan filtering. Geophysics, 32(5): 789-800.

VETTERLI M \& HERLEY C. 1992. Wavelets and filter banks: Theory and Design. IEEE Transactions on Signal Processing, 40(9): 2207-2232.

WANG W, GAO J, CHEN W \& XU J. 2012. Data adaptive ground-roll attenuation via sparsity promotion. Journal of Applied Geophysics, 83: 19-28.

YILMAZ Ö. 2001. Seismic data analysis: Processing, inversion, and interpretation of seismic data. Society of Exploration Geophysicists. 